\title{
Epithelial Receptor Cell
}

National Cancer Institute

\section{Source}

National Cancer Institute. Epithelial Receptor Cell. NCI Thesaurus. Code C13145.

A cell on the surface of the body or lining a body cavity that responds to physical and chemical stimuli by sending information to the central nervous system. 